\begin{tabular}{|l|l|}
\hline HHS PUbic ACCESS & $\begin{array}{l}\text { Author manuscript } \\
\text { Educ Econ. Author manuscript; available in PMC 2017 January 01. }\end{array}$ \\
\hline
\end{tabular}

Published in final edited form as:

Educ Econ. 2016 ; 24(4): 393-410. doi:10.1080/09645292.2015.1032891.

\title{
Health, SES, and the Timing of Education Among Military Retirees
}

\author{
Ryan D. Edwards \\ Queens College, City University of New York, Powdermaker 300, 65-30 Kissena Blvd., Flushing, \\ NY 11367 \\ Ryan D. Edwards: redwards@qc.cuny.edu
}

\begin{abstract}
The timing of education across the life cycle is differentially associated with older-age health outcomes and socioeconomic status among military retirees, a subpopulation with common levels of adolescent health but variation in educational timing. A year of education obtained before military service lowers the probability of poor health in retirement by 2.5 percentage points, while a year obtained after service reduces poor health by only 0.6 percentage point. By contrast, education raises income and wealth uniformly through vintage. This suggests that education improves health through fostering the lifelong accumulation of healthy behaviors and habits rather than raising income or wealth.
\end{abstract}

\section{Keywords}

Veterans; Health inequality; Health production; Human capital; Gap year; U.S. JEL

Classifications: I12, I20, J24

\section{Introduction}

The association between education and health has been a subject of interest since the pioneering work of Kitagawa and Hauser (1973) and remains the focus of much inquiry. A recent literature review discusses many of the insights and challenges (Eide and Showalter, 2011). In this paper I propose and outline a new frontier in this body of research: the analysis of the timing of educational attainment over the life cycle. With a unique dataset containing retrospective life histories of attainment among military retirees, I reveal cross sectional patterns that suggest a role for the timing of education in old-age health outcomes and that convey interesting new information about the life-cycle relationships between health, education, and socioeconomic status (SES) deserving of further study.

Questions remain open about causality and magnitudes of the effects of education on health,as recent reviews of the health economics literature discuss (Grossman, 2006; Cutler and Lleras-Muney, 2008; Lochner, 2011; Eide and Showalter, 2011). Elo and Preston (1996) revealed educational differentials in mortality in a multivariate setting, while Meara, Richards, and Cutler (2008) show these differentials widening over recent decades and compare them to similar trends in smoking behavior by education. Studies of compulsory schooling laws in the U.S., Canada, and the UK appear to reveal causality running from 
education into improved health (Adams, 2002; Oreopoulos, 2007; Lleras-Muney, 2005). But health shocks can also affect socioeconomic status (SES), particularly at older ages (Adams et al., 2003), and poor health in youth can reduce educational attainment (Bleakley, 2003). In the parlance of health economics, a question is to what extent education may increase "productive efficiency," the marginal effect of healthy inputs (Grossman, 1972); "allocative efficiency," the ability to make healthier decisions (Rosenzweig and Shultz, 1982); or income and wealth, which can indirectly affect health through purchases (Grossman, 1972).

I propose a new line of inquiry into these questions by examining how the timing of education over the life cycle affects the associations between educational attainment, SES, and health at older ages. Previous research in labor economics has studied how earnings respond to variation in the timing of schooling (Griliches and Mason, 1972; Griliches, 1980; Marcus, 1984; Light, 1995; Monks, 1997; Holmlund, Liu, and Skans, 2008), but no previous studies explore implications for adult health. The gap in the literature is probably due to insufficient coverage of the life cycle in longitudinal studies and few surveys of aging that ask retrospective questions about educational attainment. In this study, I examine a recent survey of military retirees that asked about educational attainment at several junctures in the life cycle. Veterans in general and military retirees in particular are interesting because they display a relatively large amount of variation in the timing of their education through life. This is partly due to past periods of conscription, the shorter duration of military careers and the need to readapt to the civilian labor force, and to educational subsidies like the G.I. Bill and other programs.

Preliminary findings based on cross-sectional patterns in these data suggest that the timing of education matters for old-age health. As one might expect for a variety of reasons, years of education acquired earlier in life are more strongly associated with good health in retirement than are years acquired later, and the marginal effects decline monotonically in age at acquisition among all subgroups, low and high ability alike. What is particularly interesting is that the marginal effects of schooling on income and homeownership do not decline so sharply, and this discordance between the marginal effects on health and on SES suggests the presence of third mechanisms. Taken in combination, these patterns suggest that education may be directly protective for health in old age through enhancing productive or allocative efficiency, and not through raising income or wealth.

This study is limited in its scope and implications by several factors. The survey I examine offers relatively few details about health, fewer about wealth, and nothing about healthy behaviors. More problematic is that I cannot robustly control for selection in these data, although I can compare results across subgroups defined by a clear measure of ability: military rank. I cannot draw identification from variation over time because of the survey design. And the variation in educational attainment in my sample is solely at the higher end of the educational distribution, the polar opposite of that in earlier studies of compulsory schooling. Thus my results here are tentative and circumscribed but also arguably provocative, and they suggest fruitful lines of further research using longitudinal datasets that have improved and evolved in recent years. 


\section{Background}

Individuals typically acquire primary and secondary education during adolescence, but higher education can often be acquired later in life. In certain countries and among particular subgroups, delay is common. Gall, Legros and Newman (2006) illustrate how the timing of education varies significantly across the OECD, with the narrowest distribution (2 years difference between the $20^{\text {th }}$ and $80^{\text {th }}$ percentiles of age at tertiary education) observed in Ireland and the widest in New Zealand, Norway, and Sweden (20 years). They and Sjögren and Saez-Marti (2004) construct theoretical models of the timing of education based on matching processes or uncertainty in returns and the price of time. Without those forces, education later in life is suboptimal in the traditional view of human capital (Becker, 1962; Mincer, 1974). Empirical estimates of the labor market costs of delaying education broadly confirm this story, in the sense that "gap years" spent earning reduced or even zero wages before acquiring education are permanently costly because they can never be recovered.

Whether the returns to additional years of education permanently depend on when they were received during the life course remains less clear. Griliches and Mason (1972) examine a cross section of veterans in a 1964 Current Population Survey and find that returns to education acquired during or after military service were insignificantly higher than returns to education received before service. Griliches (1980) and Marcus (1984) both explore the returns to interrupted schooling in the National Longitudinal Survey (NLS) of Young Men between 1966 and 1973, and neither find a penalty for interruption. More recent studies that focus on exogenous variation in the incidence of military service reveal a zero net effect for the World War II cohort (Angrist and Krueger, 1994) but evidence of negative and persistent effects on earnings for later cohorts (Angrist, 1990, 1998; Imbens and van der Klaaw, 1995). Light (1995) reveals wage penalties for delayed education among white men in the 1979 NLSY that persist for four years and then die out. After broadening the NLSY sample to include women and minorities and adopting a different statistical model, Monks (1997) finds permanent wage penalties for delay. In Swedish data collected after 1985 on cohorts born before 1973, Holmlund, Liu and Skans (2008) reveal persistent and significant effects on earnings associated with short delays in entering college.

Given the interconnections between health, income, and education, it is natural to ask how the timing of education may affect health,but few studies have explicitly done so. Building off the work of Card and Lemieux (2001), who find that draft avoidance raised attainment during the Vietnam War, Grimard and Parent (2007) report evidence that avoidance may have resulted in reduced smoking and thus better health for nonveterans. This fits recent work by Bedard and Deschênes (2006) showing higher mortality among U.S. birth cohorts with high military participation, ostensibly due to smoking. Other research reveals considerably more ambiguity about the net impact of military service on health (London and Wilmoth, 2006; Dobkin and Shabani, 2009). Given evidence of the stimulative impact of the midcentury G.I. Bill on the educational attainment of veterans (Bound and Turner, 2002; Stanley, 2003), it appears either that delayed education is less valuable for health, or the negative effect of military service on health is larger, or both are true. To date, no study has examined the effect of the G.I. Bill on veterans' health, or the effect of delayed education on health more generally. The gap in the literature may be due to the absence of a clean natural 
experiment vis-à-vis health in the context of military service. Even if drafted veterans ultimately acquire more education than nonveterans, as the literature on the G.I. Bill suggests they do, military service is likely to exert an independent effect on health through combat exposure and other channels. This would complicate any comparison of veterans to nonveterans. Differences across subgroups of veterans might be more interesting if they were subject to plausibly exogenous variation in the determinants of education. Another direction would be to focus on differences in the timing of education and health across all civilians, extending the findings of Light (1995) and others to health. In this paper, I leverage some unique retrospective data on educational attainment among military retirees.

\section{The life cycle of schooling among military retirees}

Military retirees are interesting for several reasons. Their lengthy service careers, typically 20 years or more, are evidence that their health and abilities during adolescence and young adult years must have met some baseline standard. Thus they ought to be subject to less unobserved heterogeneity in factors that affect health than the rest of the civilian population, which should help reduce omitted variable bias. MacLean and Edwards (2013) discuss some of these elements of selectivity in a recent review of research on the health of veterans.

Military retirees also exhibit a very large amount of variation in the timing of education across the life cycle. A majority receive additional education during military service, and almost a third acquire more education after retiring. Figure 1 plots education trajectories across age for all male retirees aged 40 and older with 20 years of active duty service, and also plots separate trajectories for officers and enlisted men. The data are drawn from the 2003 Survey of Retired Military (SRM), which asked retirees to retrospectively report their levels of educational attainment when they entered the military, when they retired, and at the time of survey. The 2003 SRM is a snapshot of approximately 30,000 veterans, of which 16,155 are men aged 40 or over with 20 or more years of active duty and a complete set of covariates. As I explain in the notes to Table 1, I dropped 264 individuals with full covariates who reported losing educational attainment between life stages. Responses are categories rather than years of attainment, so I translate between them using the following scheme. Less than 12 years is probably age 16 or 10th grade. A GED or high school equivalency and high school diploma are 12 years. Less than 2 years of college without a degree is 13 years. A 2-year college degree is 14 years. More than 2 years of college credits but no 4-year degree is 15 years. A 4-year college degree is 16 years. Some graduate school but no graduate degree is 17 years. A master's, doctoral, or professional degree is 20 years. An earlier survey in 1996 asks similar questions, but the public version of the 1996 SRM reports age only in two broad groupings, under or over 65 , so I focus on the 2003 survey because it measures respondents' ages in single years. Without good resolution on the age variable, it is problematic to model health and earnings, which follow strong life-cycle trajectories. MacLean and Edwards (2010) describe the dataset in greater detail.

On average, military retirees entered service at age 20 with 12.8 years of school, left service at age 43 with 15.2 years, and reported 15.8 years of schooling at survey, aged 57. As shown in the graph, this pattern of delayed attainment varies by rank. Officers entered service two years later with 14.6 years of education compared to 11.9 among enlisted men; they gained 
3.4 years of education during service as opposed to 1.8 ; and they received an additional 0.4 year rather than 0.8 year after retirement. For enlisted men, the trajectory is almost linear, while it is concave for officers.

Civilian cohorts tend to complete their education earlier in life. Figure 2 shows the trajectory of average education by age among members of the National Longitudinal Survey of Youth 1979 (NLSY 79) cohort, and among individuals in the Panel Study of Income Dynamics (PSID) born between 1945 and 1965. For both groups, educational attainment decelerates rather strongly after the mid-twenties. The slope for the NLSY 79 cohort is about 0.85 prior to age 20, 0.34 between 18 and 22, and about 0.03 after age 22. By comparison, the slopes in Figure 1 hover between 0.05 and 0.15 . Absolute levels of attainment in these two graphs are also revealing. With about 11.9 years of education by age 20 and 13.7 by age 42 , enlisted retirees are similar to the civilians in the NLSY 79 cohort in terms of their trajectories prior to retirement. But the additional 0.8 year they acquire by age 55 is unique. Retired officers have much higher levels of education than either group, and their rate of acquisition during military service is uncommonly rapid. Another interesting comparison is between the PSID and NLSY 79 data in Figure 2. The former includes many birth cohorts subject to the draft and eligible for the Vietnam-era G.I. Bill, while the latter came of age during the AllVolunteer Force. The differences in later-life educational attainment visible in Figure 2 could be attributable to patterns in military service, a topic I leave for future inquiry.

Table 1 reports more characteristics of the military regression sample I use in this paper. As shown across the columns, the timing and level of educational attainment varies strongly with rank but less so with disability, consistent with similar levels of VA disability across ranks. More than three quarters of all retirees report acquiring additional education during their military careers. Nearly a third acquired more education after retirement, with greater prevalence among enlisted men and to a lesser extent disabled retirees. The lower rows in Table 1 show that retired officers are roughly half as likely to report fair or poor health as retired enlisted men, they earn 75 to 80 percent more income, and they are 10 percent more likely to own their own home. Non-disabled retirees are only 30 percent as likely as disabled veterans to be in fair or poor health, and they earn 10 to 13 percent more income, but their homeownership is actually slightly lower. Part of these SES patterns reflect race and ethnicity; African Americans and Hispanics are disproportionately enlisted and disabled.

Compared to nonveterans, the subpopulation of military retirees is relatively unhealthy because of service-related disability. Data from the 2003 National Health Interview Survey show 15.8 percent of males over 40 report fair or poor health, compared with 18.1 percent of male veterans over 40 . Both figures are considerably lower than the 27.6 percent of male military retirees over 40 who report fair or poor health as shown in the first column of Table 1. But as revealed in the fourth column, only 11.6 percent of retirees without a VA disability rating report fair or poor health. Military retirees are thus a select group compared to all civilians, with higher education and better health conditional on service-related disability. 


\section{A regression model of health, SES, and education}

I present an extended theoretical analysis of variation in educational timing and outcomes in a related working paper (Edwards, 2010). Assume individuals maximize utility subject to three "flow" budget constraints that describe the dynamics of stocks of health $H_{t}$ and wealth $W_{t}$, and the flow of income $y_{t}$ :

$$
\begin{gathered}
H_{t}=(1-\delta) H_{t-1}+h\left(m_{t}, S_{t}\right)+\varepsilon_{t}^{H} \\
\log y_{t}=f\left(H_{t}, S_{t}\right)+\varepsilon_{t}^{Y} \\
W_{t}=(1+r) W_{t-1}+y_{t}-c_{t}-p_{t} \cdot m_{t}-T_{t} \cdot \Delta S_{t}+\varepsilon_{t}^{W}
\end{gathered}
$$

Years of schooling acquired as of time $t$ is $S_{t} ; \delta$ is the rate at which health depreciates; health production $h(\cdot)$ depends on medical spending $m_{t}$ and schooling $S_{t}$, whose prices are $p_{t}$ and $T_{i} ; c_{t}$ is other consumption; $r$ is the real interest rate; labor is supplied inelastically and normalized to 1 , and wages $f(\cdot)$ are a function of health and schooling; and the $\varepsilon^{\prime}$ s are whitenoise errors.

With information on the timing of schooling over the life cycle, I can test for vintage effects. As shown by Table 1, the SRM contains measures of retirees' stocks of education at entering the military, at leaving the military, and at survey, which roughly correspond to ages 20,45 , and 55 . The stock of education at survey can be additively decomposed:

$$
S_{55}=S_{20}+\left(S_{45}-S_{20}\right)+\left(S_{55}-S_{45}\right)=S_{20}+\Delta S_{45}+\Delta S_{55}
$$

Using equation (4) and some simplifying assumptions, I can rewrite the structural budget constraints as estimable regression equations of health, wealth, and income at the time of survey at age 55. I posit the health production function $h(\cdot)$ is linear in its arguments, and I assume a Mincerian log-linear earnings function $f(\cdot)$. I omit medical spending because it is not observed. After inserting a vector controlling for observable characteristics at survey, $X_{55}$, I estimate these versions of the structural budget equations:

$$
H_{55}=\alpha^{H}+\beta^{H} H_{45}+\eta_{20}^{H} S_{20}+\eta_{45}^{H} \Delta S_{45}+\eta_{55}^{H} \Delta S_{55}+\theta^{H} \log y_{55}+\gamma^{H} X_{55}+\varepsilon^{H}
$$




$$
\begin{gathered}
y_{55}=\alpha^{y}+\beta^{y} H_{55}+\eta_{20}^{y} S_{20}+\eta_{45}^{y} \Delta S_{45}+\eta_{55}^{y} \Delta S_{55}+\gamma^{y} X_{55}+\varepsilon^{y} \\
W_{55}=\alpha^{W}+\beta^{W} H_{55}+\eta_{20}^{W} S_{20}+\eta_{45}^{W} \Delta S_{45}+\eta_{55}^{W} \Delta S_{55}+\theta^{W} \log y_{55}+\gamma^{W} X_{55}+\varepsilon^{W}
\end{gathered}
$$

Health depends on past health, education, current income, and other characteristics; income depends on current health, education, and other characteristics; and wealth depends on current health, education, current income, and other characteristics. Endogeneity is apparent, and instrumental variables or some other approach would be necessary to fully address it. The public version of the 2003 SRM includes no geographic identifiers and no good instruments, so I focus on OLS results in this paper and check for robustness across key avenues of selection.

Of particular interest are how the $\eta$ 's, the coefficients on schooling, change by vintage and how those trajectories vary across equations (5), (6), and (7). A downward trajectory in the $\eta$ 's reveals later years of education to be less valuable than earlier years, either because of age-related reductions in its marginal productivity, positive selection of lower ability individuals, or permanent effects of gap years on stocks. If the $\eta^{H}$ s fall faster with age than the $\eta^{\nu}$ s, a simple explanation is that health is a stock that changes slowly while income is a flow. If the $\eta^{H}$ 's fall faster than the $\eta^{y}$ s and the $\eta^{W_{\text {s }}}$, a better interpretation is that education affects health more through the lifelong acquisition of protective stocks like knowledge and patterns of healthy behavior, rather than through the impact of education on income or wealth.

\section{Data and results}

Health metrics in the 2003 SRM include self-reported health status on a five-point scale, two questions about work limitations, and four indicators of functional limitations or disability. Common indexes of functional status are activities of daily living (ADLs) or instrumental activities of daily living (IADLs), the latter of which measures the ability to live independently. The four limitations measures we have in the 2003 SRM include two ADLs, walking without assistance or using stairs, and lifting or carrying something as heavy as 10 pounds; and two measures that effectively relate to IADLs, seeing words or letters in newsprint, and hearing a conversation, both with the use of corrective lenses or hearing aids. These latter metrics are not uncommon in studies of health dynamics but merit further mention. As discussed by Mazumder (2008), although vision and hearing are often found to be correlated with education, it is not obvious how education could cause improvements in those conditions rather than the reverse, except in the case of diabetes and reduced vision. Hearing problems may stem from environmental risks such as loud music or traffic noise that individuals with more education may know to avoid. On balance, it seems reasonable to include these measures in the analysis having provided some important context. 
I generate binary indicators of bad health for each of these metrics and estimate logit models, reporting marginal effects for comparability with Cutler and Lleras-Muney (2008). Earnings and household income are measured with high granular detail and minimal topcoding, and I model the log of each measure using OLS. The only measure of wealth available to estimate equation (7) is an indicator of homeownership, which I model using a logit. The vector of characteristics includes officer status, age, race, ethnicity, and marital status. I use VA disability rating as an indicator of health at 45 . The estimation sample includes men over 40 with at least 20 years on active duty.

\subsection{Full sample}

Each row in Table 2 displays estimates of the education coefficients, $\eta_{20}, \eta_{45}$, and $\eta_{55}$, from a separate health, income, or wealth regression. The first row reveals that earlier years of education are significantly more protective against self-reported fair or poor health than are later years. The marginal effect of education at entering the military is -0.0254 and significant at the 1 percent level; the coefficient on education earned after entering but before retirement is -0.0161 or about a third smaller but still highly significant; and the coefficient on post-retirement education is only -0.0059 and significant at the 5 percent level. The last coefficient is about one third the size of the marginal effect of total years of education at survey, -0.0158 , which is shown in the last column. By comparison, Cutler and LlerasMuney (2008) report marginal effects of total years of education on self-reported fair or poor health ranging from -0.0073 to -0.0152 .

A similar pattern emerges in the following 8 rows. For most of these health indicators, years of education acquired during service are protective against the dimensions of bad health in Table 2, but in each case they are also significantly less protective than years acquired before service. Education acquired after service appears to have little effect on these measures of bad health. As shown in the last column, total years of education are protective against all these conditions except difficulty hearing, but only in the case of difficulty seeing is the marginal effect of post-service education negative and significant. It is unlikely that power is an issue here; as shown in Table 1, these health conditions are generally as prevalent as selfreported fair or poor health.

Patterns in the bottom three rows reveal a different relationship between education vintage and SES outcomes. Earnings rise 5.5 percent with each year of education prior to service, then rise 5.8 percent with each year acquired during service, but they do not respond significantly to years acquired after service. Household income rises 6.4 percent with education prior to service, 6.1 percent with education during service, but only 2.7 percent with post-service education, all significant at the 1 percent level. The reduction of more than half in the marginal effect of education after retirement is highly significant, but there is no significant difference between education acquired prior to service versus during service. The divergence in results, namely how post-service education affects household income but not labor earnings, reflects sensitivity to post-service education of the respondent's income from assets, pensions, and transfers, and of the spouse's income.

There are four components of individual income in the 2003 SRM: labor earnings, asset income, pension income, and transfers. Household income is the sum of these across 
respondent and spouse. The respondent's transfer payments are individually the most sensitive to post-service education, but excluding them does not change the qualitative result. Transfer income in the 2003 SRM includes all of the following as a single item: supplemental security income, unemployment insurance, civilian or military disability, worker's compensation, the G.I. Bill, food stamps, Aid to Families with Dependent Children (AFDC) or welfare, and child support or alimony. The components of spousal income that vary significantly with the respondent's post-service education are labor and pension income. The last row in Table 2 shows that the probability of home ownership responds equally to education across all vintages including post-service. Although there is a slight decline in marginal effects with age, the differences are not statistically significant. Each additional year of education raises the probability of home ownership by about 0.6 percentage point.

\subsection{Subsamples across rank and disability}

In Table 3, I reestimate equations (5), (6) and (7) on subsamples defined first by rank and then by VA disability status. Rank may proxy ability, and VA disabilities trigger more generous educational subsidies. For both officers and enlisted men, the health effects of education fall strongly with age. This is more pronounced among enlisted men, for whom the marginal effects fall by half from -0.0381 to -0.0194 , both highly significant, and then by a third to -0.0070 , significant only at the 10 percent level. By contrast, income and wealth effects of education are stable prior to retirement for both groups, while post-service education matters only for the income and housing of enlisted men. As in Table 2, the effect of post-service education on income is only about half the size of effects prior to retirement for enlisted men, while it is insignificant for officers. If ability bias were driving the downward-sloping vintage effects of education, one would expect them to vanish or at least lessen when the sample was constrained to the group with higher ability, namely officers. But here we find no such evidence.

In the bottom panel of Table 3, groups stratified by VA disability exhibit similar patterns. The chief differences from the top panel are that both disability groups benefit from postservice education in terms of income and home ownership, and retirees without a VA disability experience health benefits. But among both groups, there are significant vintage effects of schooling on health earlier in the life cycle, while vintage effects of schooling on income are only important post-service. There is limited evidence of any vintage effects on home ownership; there is a larger effect of pre-service education for the non-disabled. For retirees with no VA disability, the marginal effect of education on health stays the same during and after service, while it falls for disabled retirees. In isolation, this result might suggest a role for VA disability in producing downward-sloping marginal effects. But we still see a reduction in the marginal effect among the non-disabled group after entering the military. Thus vintage effects of education on health appear not to be due to service-related disability.

\subsection{Subsamples of returning students}

Another feasible strategy to address selection is to reestimate the models among subgroups that have either returned for additional education or not, drawing identification from differing treatment intensity among the treated, rather than from differences between 
treatment and control groups, which are not well defined here. As shown in panels A and B of Figure 3, there is considerable variation in the amount of extra education earned among both subgroups of returning students, those who acquired additional education during service (panel A), and those who acquired more post-service (panel B). If the determinants of reentering school differ from the determinants of how much schooling to receive upon having returned, then this approach will help address the problem of endogeneity in the decision to return.

The top panel in Table 4 explores how vintage effects of education may depend on whether the retiree returned for post-service education. Few qualitative differences from the baseline results in Table 2 are apparent, which suggests they were fairly robust to this form of selection. Both post-service returners and non-returners experience significantly reduced marginal effects on health of education received during service, -0.0267 and -0.0134 , compared to that received before, -0.0469 and -0.0204 . In both cases, the marginal effects fell by about 40 percent over roughly 25 years. For post-service returners, the marginal effect on health of post-service schooling is similar in magnitude to that in Table 2, but it is insignificant. Both groups consistently benefit from schooling prior to retirement in terms of income, and marginal effects on home ownership are stable if also insignificant in the case of returners. Those who obtain education post-service benefit from it in terms of income, but the marginal effect is again significantly lower than for earlier vintages of education, much as in Table 1. The bottom panel of Table 4 presents estimates among groups defined by whether they obtained education during service. Vintage effects of education are clear and large in the health regressions, while in the income regressions there is no significant vintage effect until after service.

\section{Discussion}

Military retirees exhibit much heterogeneity in the timing of their education, SES, and health following their retirement from the military. Among this subgroup, the health returns to education are monotonically diminishing in the age at acquisition. The marginal effect on the probability of self-reported fair or poor health of an additional year of education acquired before military service begins, around age 20 , is -0.025 . It diminishes to -0.016 for education acquired during service, usually up to about age 45 , and then to -0.006 for education acquired after retirement and by the time of survey, around age 55 . Based on the midpoints of these age ranges, this trajectory represents an average rate of decline of about 0.5 percentage point each decade. Similar patterns emerge for the other measures of bad health in the 2003 SRM. For many of these, which focus on functional limitations, education acquired post-service has no significant effect at all, while education during service remains significantly protective, but less so than pre-service education.

Vintage effects are different for income and wealth. The marginal effects on income of education acquired before or during military service are roughly constant at about 0.06 , while post-service education insignificantly affects earnings and has half its earlier effect on household income. Marginal effects on the probability of home ownership tend to be constant across educational vintage at about 0.06 . Unlike income, wealth is a stock like health, and both should display permanent effects of temporarily lower inflows. That health 
but not wealth is permanently lowered by schooling delays is supportive of the notion that education affects health through non pecuniary channels. If education raised health by increasing income and wealth, education that earns a particular amount of present-value wealth should enhance health the same regardless of when the education was acquired. The findings that both early and later-life education are interchangeably important for income and wealth, while early-life education is more valuable for health, is not supportive of this perspective. It is more consistent with the results of Adams et al. (2003), who find that at older ages, causality runs more from health into wealth rather than the reverse. Perhaps laterlife education brings financial rewards, but the die has been cast in terms of health. Education may affect adult health more through a lengthy process of building up healthy stocks of knowledge of healthy behaviors. This is consistent with the concept of health capital (Grossman, 1972), but it also suggests that the depreciation of health or healthy knowledge must be small relative to the flow of new health investments, since new education would presumably change the latter immediately.

Education obtained at different ages probably brings association with very different peer groups. Health economists suspect that the quality of peer groups may be important for developing or transmitting healthy knowledge and behavior (Cutler and Lleras-Muney, 2008; 2010; Fletcher and Frisvold, 2011). To what extent these factors may be important for this specific context, or for life-cycle patterns in the marginal effect of education on health more generally, remains unclear and would be an interesting direction for future research.

Results are robust across a broad array of subsamples that cut along the lines most likely to be important for selection. Patterns are broadly similar for officers and for enlisted men, which suggests that ability bias may not be important. Among retirees without a VA disability, the marginal effect of education on health does not fall again after retirement but was already half as large as before service. Retirees with VA disabilities, the majority of the sample, experience larger drops in the protective effects of post-service education but consistent declines through life. The age trajectory of marginal effects is also strongly declining within subgroups that choose to seek more education. In all of these cases, the marginal effects of education on health decline monotonically with age, while the effects on income and wealth either remain stable or stay constant before declining only after service.

The similarity of health returns across many subgroups is reminiscent of the finding that the marginal benefits to earnings of education do not vary substantially across individuals, or with ability (Card, 2001). It is also consistent with results on the response of health outcomes to policy-driven shocks in educational attainment (Adams, 2002; Lleras-Muney, 2005). Here, there appears to be some variation across subgroups in the marginal benefits of education of a particular vintage, at least in health if not in income or home ownership. But the age trajectories of these marginal benefits are very similar across all subgroups.

Whether these results generalize to a broader setting or are specific to military retirees, a special group that frequently engages in later-life education, is unclear. Given more widespread dispersion in the timing of education in other OECD countries (Gall, Legros and Newman, 2006), a fruitful next step may be to examine foreign datasets. Results also suggest it is worthwhile to examine health dynamics and education timing in richer U.S. panel data 
whenever education timing can be measured and the follow-up is long enough to capture variation in adult health outcomes.

\section{Acknowledgments}

I am grateful to Michael Hurd, Alair MacLean, and Michael Grossman for insights and guidance on this topic, to seminar participants at Queens College, and to several anonymous referees for helpful comments. This research was supported by grant R03AG028277 from the National Institute on Aging. The content is solely the responsibility of the author and does not necessarily represent the official views of the National Institute on Aging or the National Institutes of Health.

\section{References}

Adams, Peter; Hurd, Michael D.; McFadden, Daniel; Merrill, Angela; Ribeiro, Tiago. Healthy, wealthy, and wise? Tests for direct causal paths between health and socioeconomic status. Journal of Econometrics. 2003; 112(1):3-56.

Adams, Scott J. Educational Attainment and Health: Evidence from a Sample of Older Adults. Education Economics. 2002; 10(1):97-109.

Angrist, Joshua D. Lifetime Earnings and the Vietnam Era Draft Lottery: Evidence from Social Security Administrative Records. American Economic Review. 1990; 80(3):313-336.

Angrist, Joshua D. Estimating the Labor Market Impact of Voluntary Military Service Using Social Security Data on Military Applicants. Econometrica. 1998; 66(2):249-288.

Angrist, Joshua D.; Krueger, Alan B. Why Do World War II Veterans Earn More than Nonveterans? Journal of Labor Economics. 1994; 12(1):74-97.

Becker, Gary S. Investment in Human Capital: A Theoretical Analysis. Journal of Political Economy. 1962; 70(5):S9-S49.

Bedard, Kelly; Deschênes, Olivier. The Long-Term Impact of Military Service on Health: Evidence from World War II and Korean War Veterans. American Economic Review. 2006; 96(1):176-194.

Bleakley, Hoyt. Disease and Development: Evidence from the American South. Journal of the European Economic Association. 2003; 1(2/3):376-386.

Bound, John; Turner, Sarah. Going to War and Going to College: Did World War II and the G.I. Bill Increase Educational Attainment for Returning Veterans? Journal of Labor Economics. 2002; 20(4): 784-815.

Card, David. Estimating the Return to Schooling: Progress on Some Persistent Econometric Problems. Econometrica. 2001; 69(5):1127-1160.

Card, David; Lemieux, Thomas. Going to College to Avoid the Draft: The Unintended Legacy of the Vietnam War. American Economic Review. 2001; 91(2):97-102.

Cutler, David M.; Lleras-Muney, Adriana. Education and Health: Evaluating Theories and Evidence. In: Schoeni, Robert F.; House, James S.; Kaplan, George A., editors. Making Americans Healthier: Social and Economic Policy as Health Policy. Harold Pollack New York: Russell Sage; 2008. p. 29-60.

Dobkin, Carlos; Shabani, Reza. The Health Effects of Military Service: Evidence from the Vietnam Draft. Economic Inquiry. 2009; 47(1):69-80.

Edwards, Ryan D. Health, Income, and the Timing of Education Among Military Retirees. NBER Working Paper. 2010; 15778

Eide, Eric R.; Showalter, Mark H. Estimating the relation between health and education: What do we know and what do we need to know? Economics of Education Review. 2011; 30(5):778-791.

Elo, Irma T.; Preston, Samuel H. Educational Differentials in Mortality: United States 1979-1985. Social Science \& Medicine. 1996; 42(1):47-57. [PubMed: 8745107]

Fletcher, Jason M.; Frisvold, David E. College selectivity and young adult health behaviors. Economics of Education Review. 2011; 30(5):826-837.

Gall, Thomas; Legros, Patrick; Newman, Andrew. The Timing of Education. Journal of the European Economic Association. 2006; 4(2-3):427-435. 
Griliches, Zvi. Schooling Interruption, Work While in School and the Returns from Schooling. Scandinavian Journal of Economics. 1980; 82(2):291-303.

Griliches, Zvi; Mason, William M. Education, Income, and Ability. Journal of Political Economy. 1972; 80(3):S74-S103.

Grimard, Franque; Parent, Daniel. Education and Smoking: Were Vietnam War Draft Avoiders Also More Likely to Avoid Smoking? Journal of Health Economics. 2007; 26(5):896-926. [PubMed: 17482299]

Grossman, Michael. On the Concept of Health Capital and the Demand for Health. Journal of Political Economy. 1972; 80(2):223-255.

Grossman, Michael. Education and Nonmarket Outcomes. In: Hanushek, Eric; Welch, Finis, editors. Handbook of the Economics of Education. Vol. 1. Amsterdam; North Holland: 2006. p. 577-628.

Holmlund, Bertil; Liu, Qian; NordströmSkans, Oskar. Mind the Gap? Estimating the Effects of Postponing Higher Education. Oxford Economic Papers. 2008; 60(4):683-710.

Imbens, Guido; van der Klaaw, Wilbert. Evaluating the Cost of Conscription in The Netherlands. Journal of Business and Economic Statistics. 1995; 13(2):207-215.

Kitagawa, Evelyn M.; Hauser, Philip M. Differential Mortality in the United States: A Study in Socioeconomic Epidemiology. Cambridge, MA: Harvard University Press; 1973.

Light, Audrey. The Effects of Interrupted Schooling on Wages. Journal of Human Resources. 1995; 30(3):472-502.

Lleras-Muney, Adriana. The Relationship Between Education and Adult Mortality in the United States. Review of Economic Studies. 2005; 72(1):189-221.

Lochner, Lance. Non-Production Benefits of Education: Crime, Health, and Good Citizenship. NBER Working Paper. 2011; 16722

London, Andrew S.; Wilmoth, Janet M. Military Service and (Dis)Continuity in the Life Course: Evidence on Disadvantage and Mortality From the Health and Retirement Study and the Study of Assets and Health Dynamics Among the Oldest-Old. Research on Aging. 2006; 28(1):135-159.

MacLean, Alair; Edwards, Ryan D. The Pervasive Role of Rank in the Health of U.S. Veterans. Armed Forces \& Society. 2010; 36(5):765-785. [PubMed: 21113413]

MacLean, Alair; Edwards, Ryan D. Health, Aging, and the Post-Service Life Cycles of Veterans. In: Amara, Jomana; Hendricks, Ann, editors. Military Medical Care: From Pre-Deployment to PostSeparation. Abingdon: Routledge; 2013.

Marcus, Richard D. Measuring the Rate of Return to Interrupted Schooling. Journal of Educational Statistics. 1984; 9(4):295-310.

Mazumder, Bhashkar. Does Education Improve Health: A Reexamination of the Evidence from Compulsory Schooling Laws. Economic Perspectives. 2008; 33(2):2-16.

Meara, Ellen; Richards, Seth; Cutler, David. The Gap Gets Bigger: Changes in Mortality and Life Expectancy, By Education, 1981-2000. Health Affairs. 2008; 27(2):350-360. [PubMed: 18332489]

Mincer, Jacob. Schooling, Experience, and Earnings. New York: Columbia University Press; 1974.

Monks, James. The Impact of College Timing on Earnings. Economics of Education Review. 1997; 16(4):419-423.

Oreopoulos, Philip. Do dropouts drop out too soon? Wealth, health and happiness from compulsory schooling. Journal of Public Economics. 2007; 91(11-12):2213-2229.

Rosenzweig, Mark R.; Schultz, T Paul. The behavior of mothers as inputs to child health: the determinants of birth weight, gestation, and rate of fetal growth. In: Fuchs, Victor R., editor. Economic Aspects of Health. Chicago: University of Chicago Press for the National Bureau of Economic Research; 1982. p. 53-92.

Sjögren, Anna; Saez-Marti, Maria. On the Timing of Education. Research Institute of Industrial Econonomics Working Paper No 614. 2004:614.

Stanley, Marcus. College Education and the Midcentury GI Bills. Quarterly Journal of Economics. 2003; 118(2):671-708. 


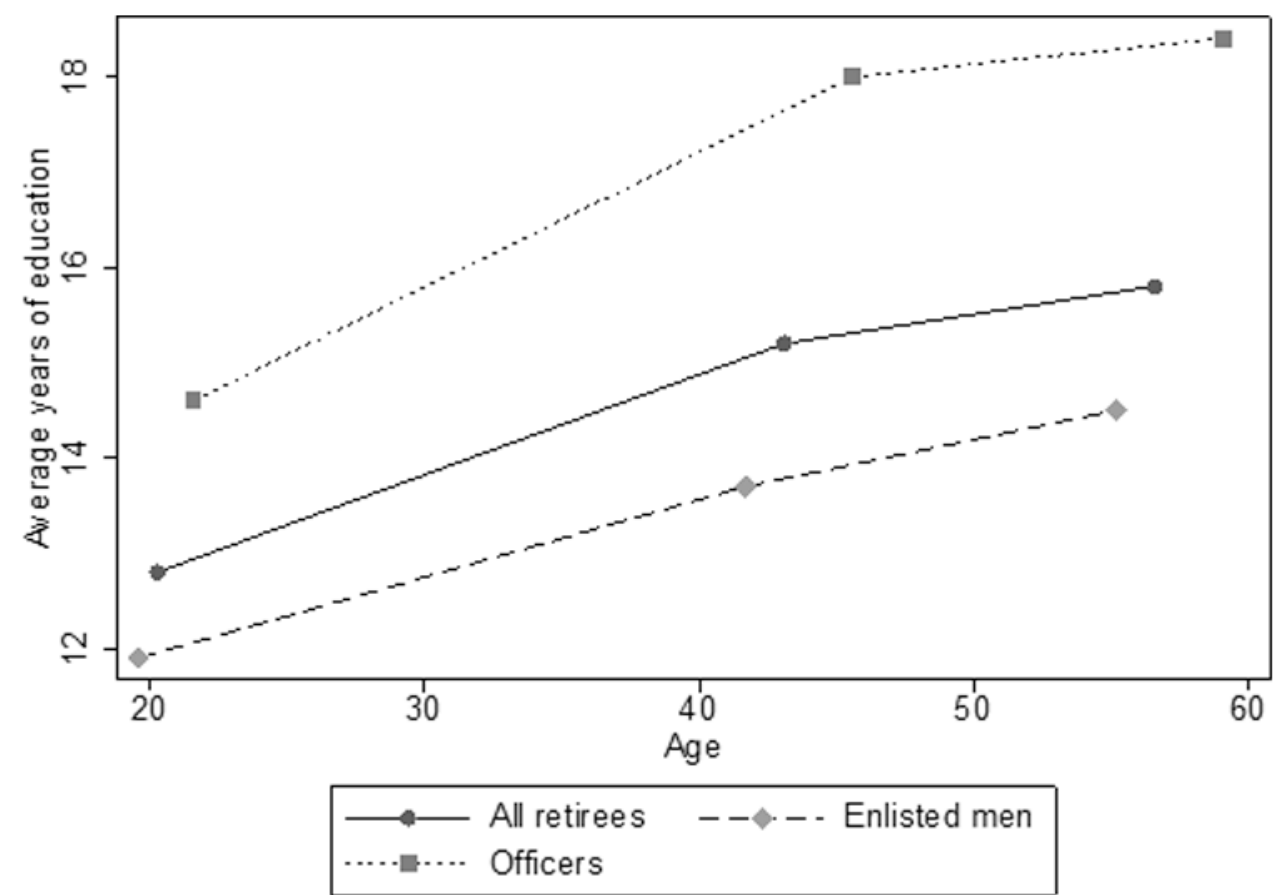

Figure 1. Average education among military retirees by age and rank

Source: 2003 Survey of Military Retirees and author's calculations. The universe is all male retirees with at least 20 years on active duty aged 40 and older. The data include age at survey in single years; age at retirement is calculated using age at survey minus an estimate of the year of retirement, which is reported in 5-year intervals; age at entering is calculated as age at survey minus single years spent on active duty. 


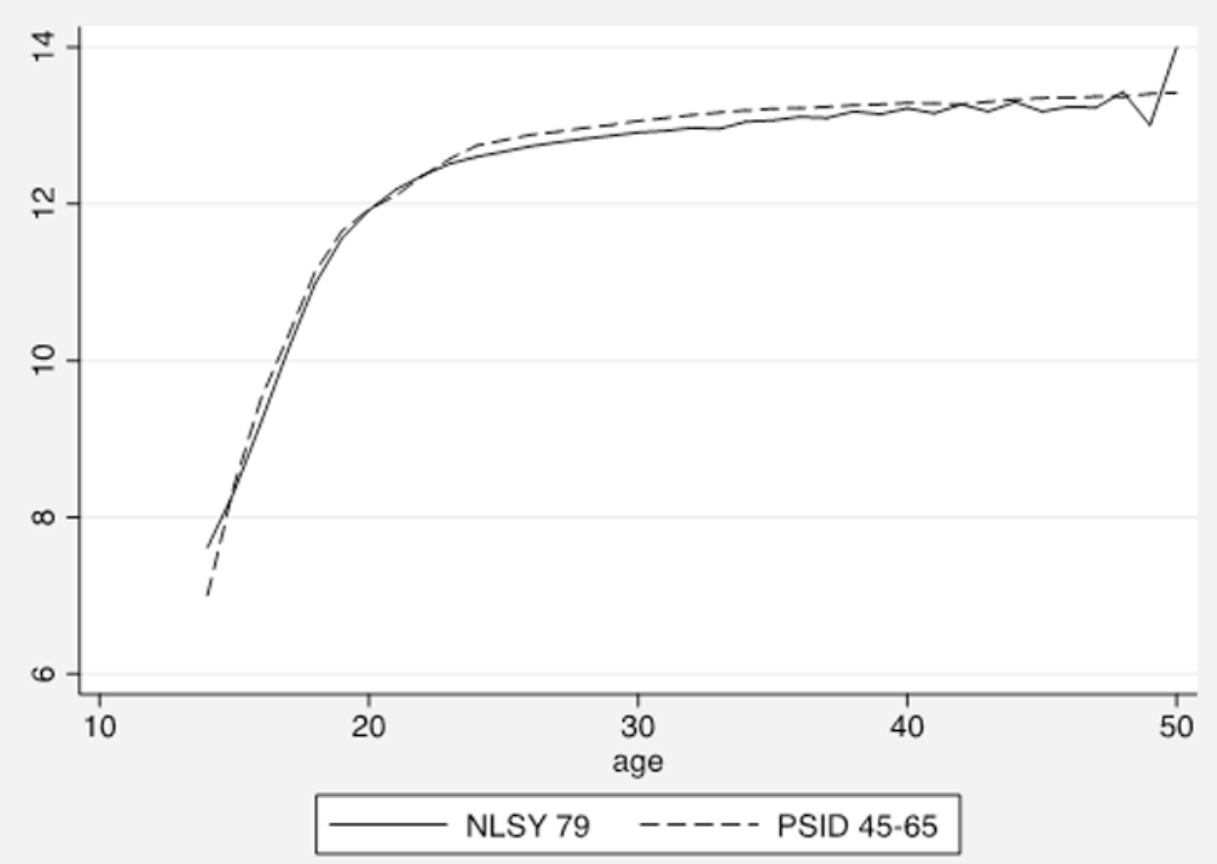

Figure 2. Average education among civilian cohorts by age Sources: National Longitudinal Survey of Youth 1979 (NLSY 79), Panel Study of Income Dynamics, and author's calculations. The universe in the former is all members of the NLSY 79 cohort with education data; in the latter, it is all PSID respondents born between 1945 and 1965. 
A

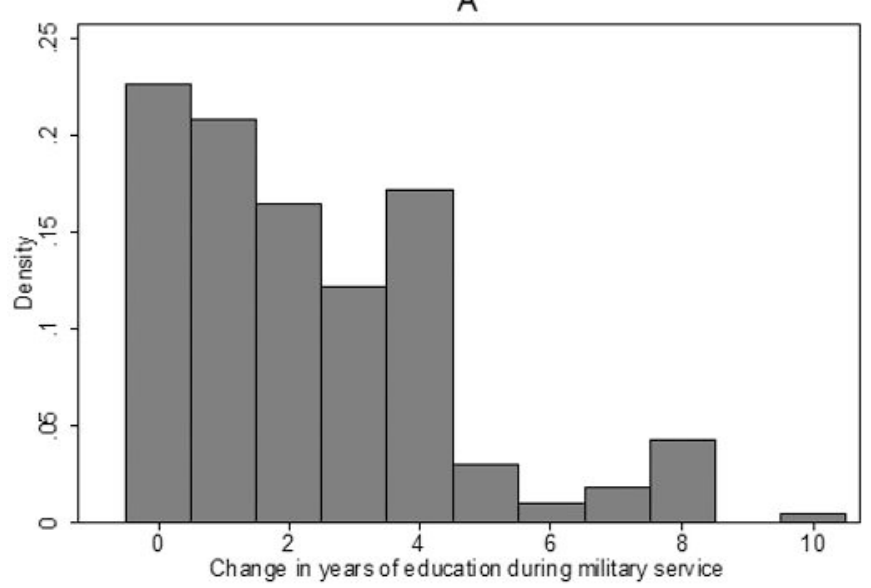

B

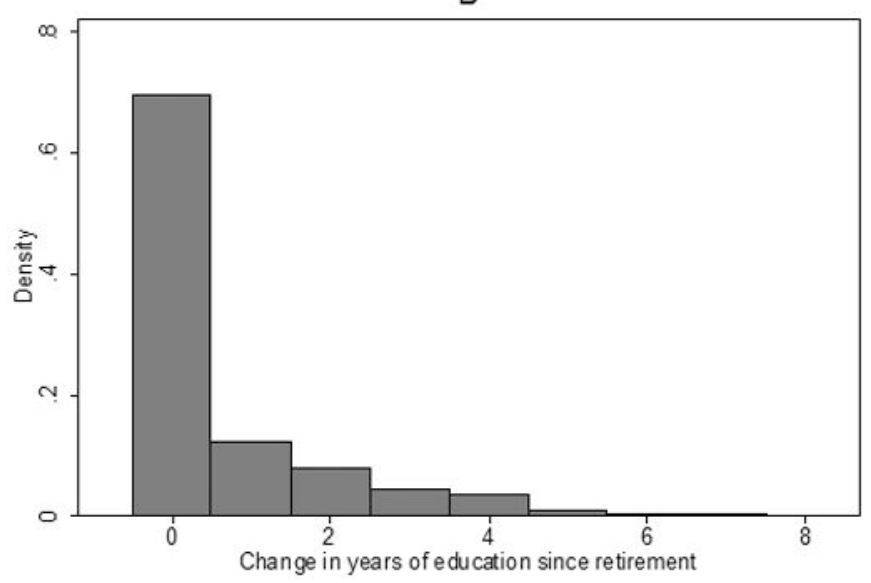

Figure 3. Distributions of additional education acquired during and after military service Source: 2003 Survey of Military Retirees and author's calculations. The universe is all male retirees with at least 20 years on active duty aged 40 and older. 


\section{을 \\ 골}

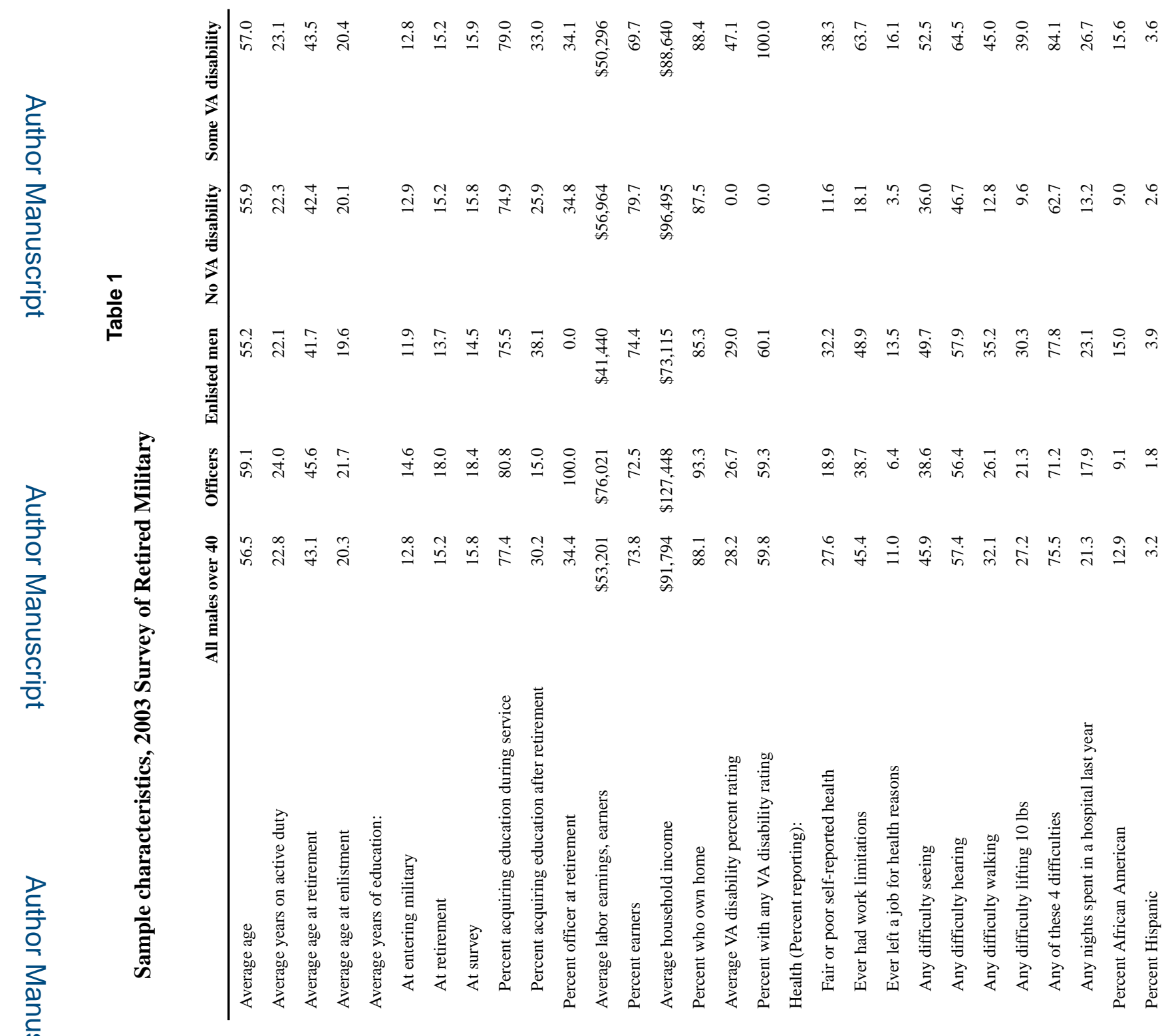

Educ Econ. Author manuscript; available in PMC 2017 January 01. 


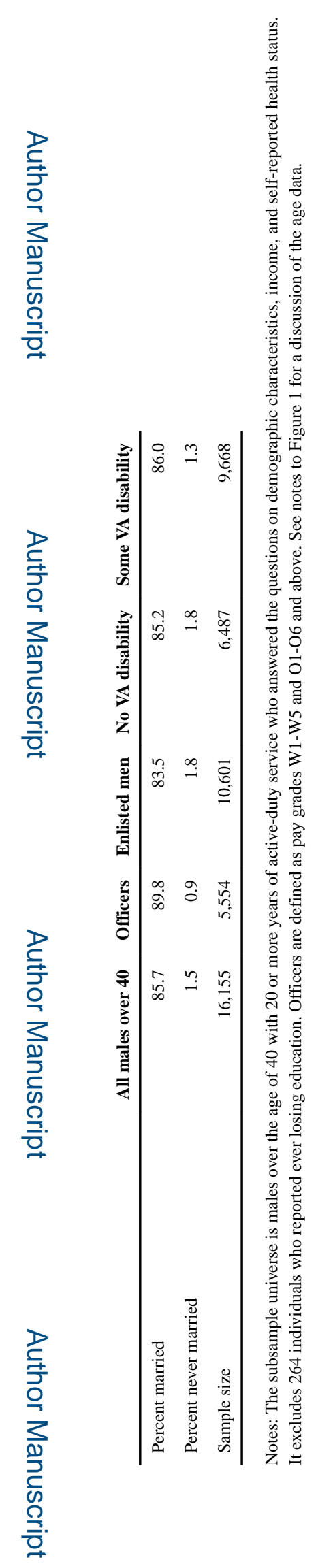

Educ Econ. Author manuscript; available in PMC 2017 January 01. 


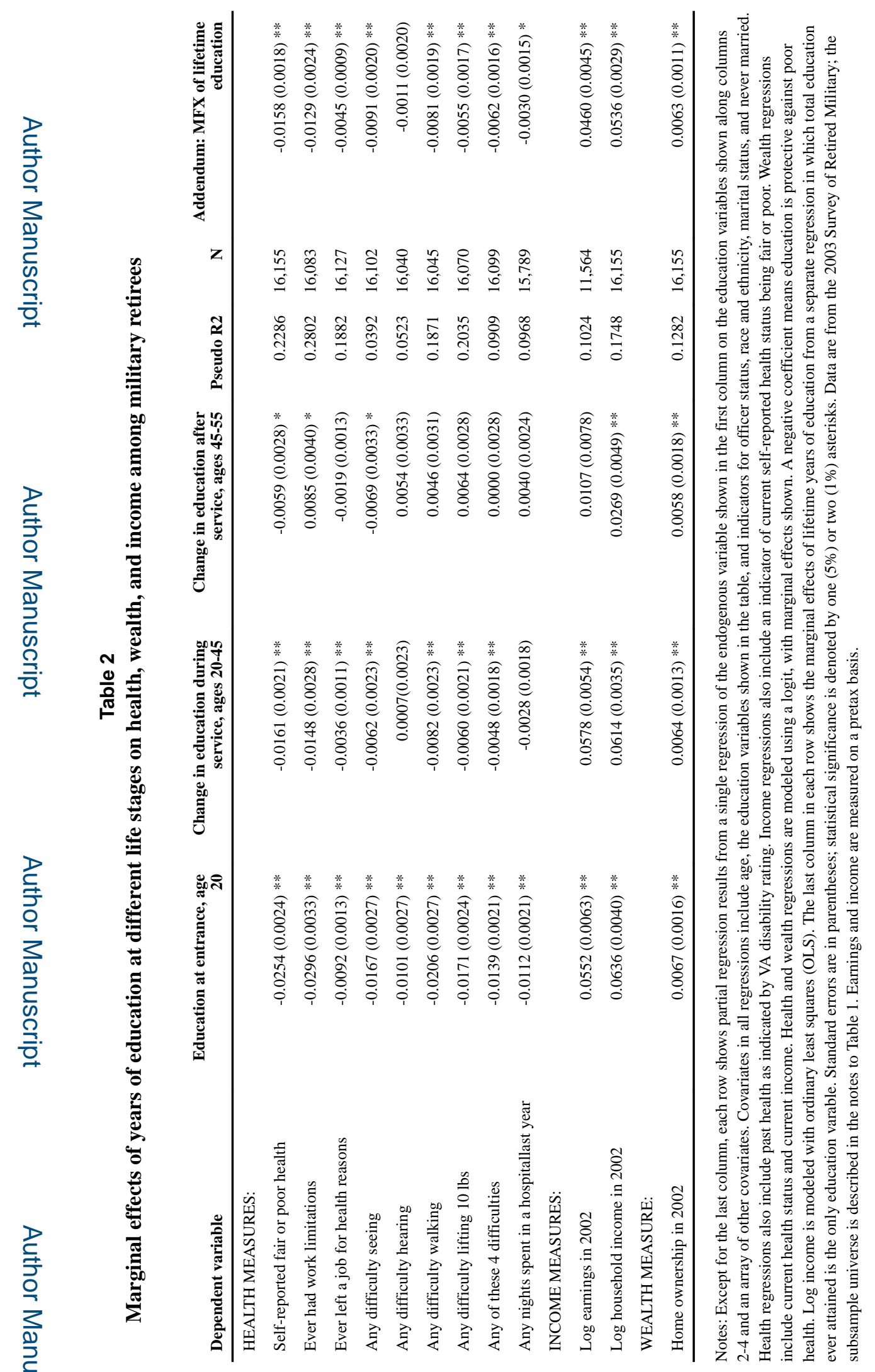

Educ Econ. Author manuscript; available in PMC 2017 January 01. 


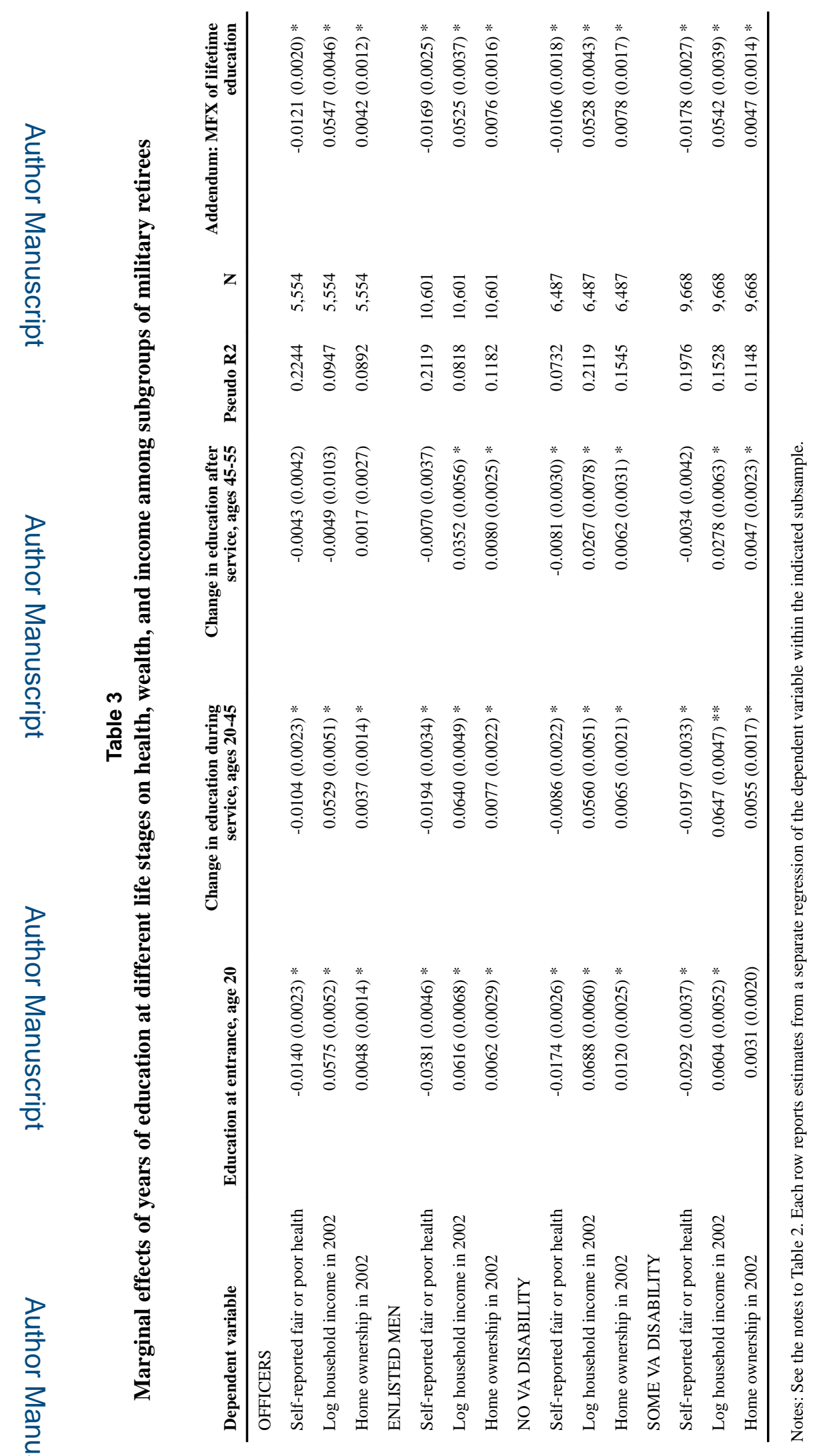

Educ Econ. Author manuscript; available in PMC 2017 January 01. 


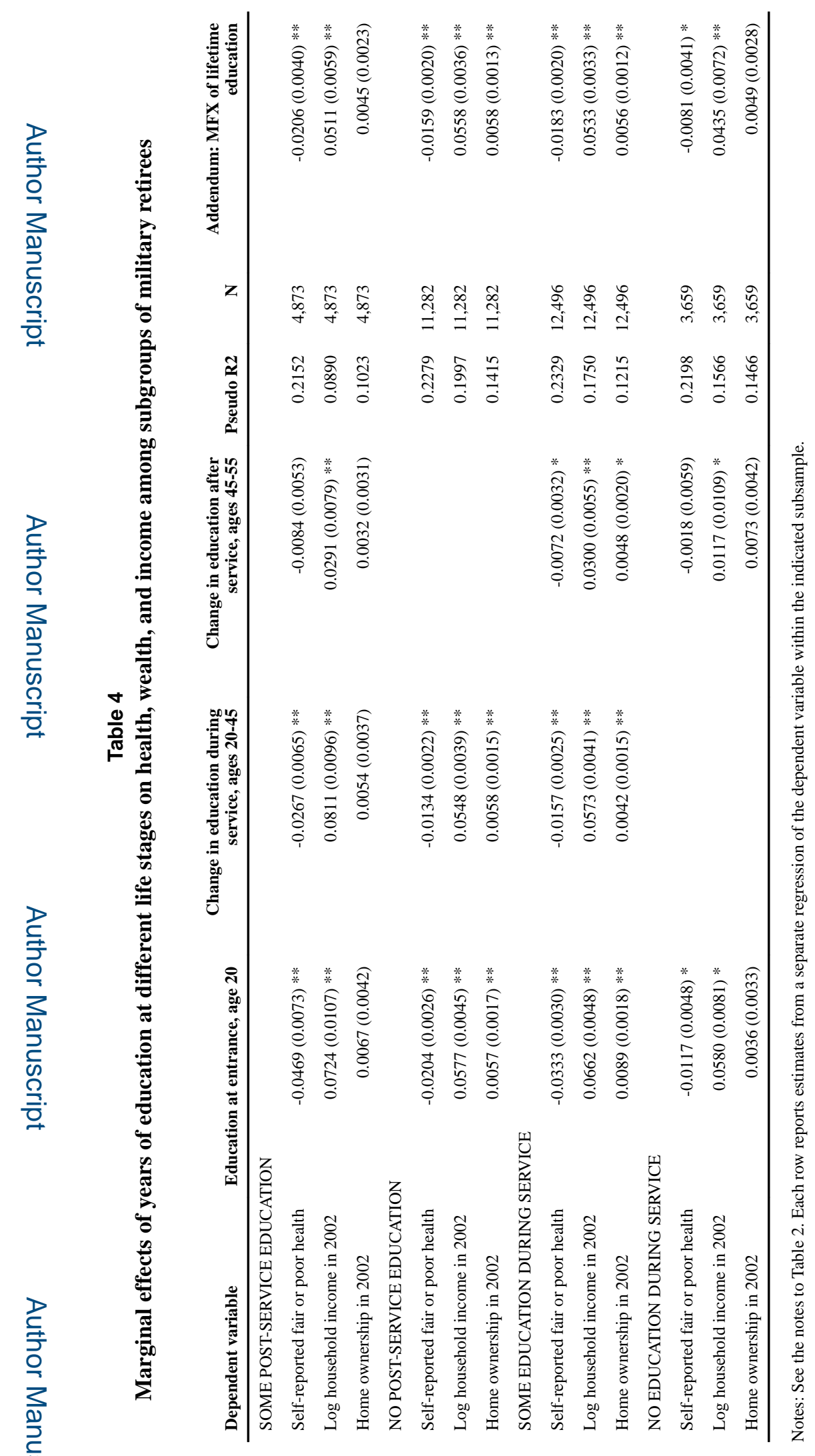

Educ Econ. Author manuscript; available in PMC 2017 January 01. 